\title{
Opinion
}

\section{Mental Health, Mass Media and Stigma Reduction.}

\author{
Upadhyaya KD
}

Senior Psychiatrist, Kathmandu Model Hospital \& Advisor, CMC-Nepal

Email Corresponding author: drkapilupadhyaya@gmail.com

Mental illness is not a personal weakness. Various factors like genetic, biological, psychological, social and environmental factors come together to cause mental disorders. We have the scientific knowledge to help people with mental disorders. New understanding of mental disorders offers new hope to the mentally ill people and their families. Effective interventions are available for mental disorders but are not accessible to the majority of those who need them.

There is great deal of stigma and discrimination against people with mental disorder in our country. People suffering from mental illness are often projected with messages and images in a negative, inaccurate, or discriminatory manner. Such attitudes are mostly due to ignorance and insensitivity. Due to lack of understanding about mental disorders, many people try to avoid psychiatric consultation as far as possible. It is very important that the public be informed and educated about mental disorders and the available services. They are also entitled to know their rights of treatment.

In a country like Nepal, where the mental health service is not well developed and public awareness is very low, majority of mental disorders and epilepsy patients are taken to faith healers for treatment. To develop more positive community attitudes and behaviours towards people with mental disorder, public education and information about mental disorders are the most important.

Various forms of mass media can be used to promote more positive community attitudes and behaviors towards people with mental disorders. Research done in other countries has shown that most people learn about mental disorders from media sources. So, mass media is very important to raise awareness and to reduce misconceptions. These days, mass media are used to educate patients, students, health professionals, consumer groups, nongovernmental organizations and the population at large about mental disorders in many countries.

There is definite influence of mass media in shaping the mental health beliefs, attitude and behavior of the people. However, if the mass media project negative images of mental illness and the mental health professionals, stigma and misconceptions about mental disorders will further increase.

Fighting stigma also requires public information campaigns to educate and inform the community about the nature, extent and impact of mental disorders in order to dispel common myths and encourage more positive attitudes and behaviours. ${ }^{1}$

Some viewers of movies and television serials take the fantasies as the real. Young generation boys and girls often like to dress up like the heroes and heroines of the movies. The advertisement sectors play a major role in the promotion of consumer products as the viewers are unconsciously attracted towards the advertised products. So the electronic Medias like movies and tele-serials have to be especially careful not to show the negative images of mentally ill people.

The Media often portrays suicide in a glamorous and biased manner, normalizing the acts, and thus prompting the vulnerable and ambivalent individuals to opt for this method in times of distress. A Swiss study found that suicide is clearly treated as a major topic of news sensations in some of the leading dailies. There is a reason of concern in view of the danger of imitation effects, as the media reports serve as the role models. ${ }^{2}$

Suicide is a major public health problem mostly due to untreated and improperly treated mental disorders. Media reporting of attempted and completed suicide cases should be without sensationalization and dramatization. Media reporting has to be educative to the public that encourages help seeking in right time and right place. 
A leading psychiatrist, Dr Peter Byrne, a researcher in the field of stigma of mental illness, and a film expert Sue baker, have started time to change and advocacy group. Their slogan is "Let's end mental health discrimination". The report states that characters with mental health problems are being depicted as more demonic and crueler than at any time in movie history. 3,4

A workshop with the journalists, movie makers (including tele-serials) and mental health professionals will be beneficial for proper reporting of mental health issues in the media.

The first step to raise awareness through mass media is the preparation of information materials about mental health and mental health care. Possible actors in this field are Psychiatrist's Association of Nepal (PAN), National Health Education Information and Communication Center (NHEICC) and NGO's working in the field of mental health. School mental health programme is also very useful to raise awareness in students and teachers about mental health. The execution of awareness raising through mass media has to be given in the hands of media professionals. At least one message should be delivered through the radio and in the newspaper, and once in a month through Television.

Indicators of success of such awareness programme will be the increase in number of mental disorder patients and their family members at the service centers. It is also important that when patients are brought for treatment, proper treatment should be available. In other words awareness raising and service has to go hand in hand.

\section{References:}

1. The World Health Report 2001: Mental Health New Understanding, New Hope Pp 98 Raising public awareness.

2. Michel K, Frey C, Schlaepter TE, Valach L; Suicide reporting in Swiss print media, Frequency, form and content of articles. Eur J Public Health 1995;5: 199203

3. Screening madness, available from: http//www.mind.org.uk/assets/0000/3963/time_to_ch ange_screening_madness.pdf.

4. Available from: http//www.time-tochange.org.uk/news/mental-health - stereotypesmovies-crueler-ever-new-report-claims. 